\title{
Quantification of Histamine by Postcolumn Fluorescence Detection High-Performance Liquid Chromatography Using Orthophthalaldehyde in Tetrahydrofuran and Reaction Mechanism
}

\author{
Kazuo KURUMA*, Eizou HiraI*, Kiyohisa UChIDA*, Junko KIKUCHI** and Yoshihiro TeruI** \\ *Diagnostic Science Department, Shionogi \& Co., Ltd., Settsu, Osaka 566, Japan \\ **Shionogi Research Laboratories, Shionogi \& Co., Ltd., Fukushima, Osaka 553, Japan
}

\begin{abstract}
For quantification of histamine, we developed a highly specific and sensitive method of postcolumn fluorescence detection HPLC using a tetrahydrofuran solution of orthophthalaldehyde. Its detection limit was $2-5 \mathrm{pg}$. This method was applied to the measurement of histamine in human blood and urine samples. Analysis by LC/MS and NMR suggested that the fluorophore in this method has an isoindole structure.
\end{abstract}

Keywords Histamine, ion-exchange high-performance liquid chromatography, postcolumn, orthophthalaldehyde, tetrahydrofuran, fluorescence detection, fluorophore, liquid chromatography/mass spectrometry, nuclear magnetic resonance

Quantification of histamine in the blood and urine requires sensitive analysis methods because of its low concentration. Enzyme immunoassay and radio immunoassay have been used, but their specificity remains a problem as the antibody used often shows high crossreactivity with 3-methylhistamine, the main metabolite of histamine in vivo. In recent years, high-performance liquid chromatography (HPLC) has been applied to the measurement of histamine. In this method, postcolumn fluorescence detection ${ }^{1}$ using a two-step condensation reaction with orthophthalaldehyde (OPA) under alkaline conditions followed by acidic conditions ${ }^{2}$, has been used. Although the specificity of this method for histamine is high, the sensitivity and reproducibility are still problems in terms of the transfer of the reagents and the stability of OPA in aqueous solutions.

We were able to overcome these problems by evaluating the HPLC conditions and developing a method with high sensitivity and reproducibility for measuring histamine in human blood and urine. We decided to use OPA, which is present as the cyclic hemiacetal form in protic solvents such as water and alcohol, but as the aldehyde form in aprotic solvents such as $\mathrm{CHCl}_{3}, \mathrm{CH}_{3} \mathrm{CN}$ and tetrahydrofuran (THF). ${ }^{3}$ We considered that the reaction of OPA with histamine would proceed primarily via the aldehyde form and used OPA solution in an aprotic solvent for the postcolumn reaction. Based on our findings, we propose the structures of the fluorophore and the mechanism of its formation in this reaction.

\section{Experimental}

\section{Reagents}

Histamine diphosphate and histamine were obtained from Wako Pure Chemicals Industries (Osaka, Japan). The other biogenic amines were of reagent grade. All amines were used as $0.01 \mathrm{M}$ perchloric acid solution. The other reagents and solvents were of commercially available reagent grade, HPLC grade and spectroscopic grade. TLC plate Silica Gel (F-254, $0.25 \mathrm{~mm}$ and $0.5 \mathrm{~mm}$ thick, E. Merck, Darmstadt, Germany) was used.

\section{Equipment}

A pump (L-6200 Intelligent Pump, Hitachi, Tokyo, Japan) connected to a degassing device (Shodex Degas, Showa Denko, Tokyo, Japan), a fluorescence HPLC monitor (RF-535, Shimadzu, Kyoto, Japan), a column oven (CTO-6A, Shimadzu), an auto injector (712 WISP, Waters, Milford, MA, USA) and a data processor (Chromatopak, C-R5A, Shimadzu) were used. The OPA solution was delivered using a precision metering pump (A-60-S, Eldex, San Carlos, CA, USA), and a ninhydrin coil (Waters) was used as the reaction coil. Histamine-OPA products were analyzed using a system consisting of a fluorescence spectrophotometer (F-1000, Hitachi) connected to a chromatograph with a UV detector (Vista 5500, Varian, Palo Alto, CA, USA). UV spectra were measured with this HPLC system connected to a photodiode array detector (990J, Waters) and fluorescence spectra were measured with a fluorescence spectrophotometer (F-4010, Hitachi). LC/MS was 
performed using a system consisting of an LC-APCI interface connected to a mass spectrometer (M-2000A, Hitachi), and ${ }^{1} \mathrm{H}-\mathrm{NMR}$ and ${ }^{13} \mathrm{C}-\mathrm{NMR}$ using an XL-400 and a UNITY-600 (Varian).

\section{Measurement}

HPLC conditions. A TSKgel Catecholpak $(6.0 \mathrm{~mm}$ i.d. $\times 15 \mathrm{~cm}$, TOSOH, Tokyo, Japan) was used as the column. The column temperature was $40^{\circ} \mathrm{C}$, and $0.2 \mathrm{M}$ propionate buffer $(\mathrm{pH} 4.5)$ containing $0.086 \mathrm{M} \mathrm{NaCl}$ as the eluent was delivered at a flow rate of $1.0 \mathrm{ml} / \mathrm{min}$. As the postcolumn reagent, THF solution of $0.1 \% \mathrm{OPA}$ was delivered at a flow rate of $0.6 \mathrm{ml} / \mathrm{min}$. The reaction temperature was $40^{\circ} \mathrm{C}$, and detection was done at an excitation of $360 \mathrm{~nm}$ and an emission of $430 \mathrm{~nm}$. Primary amines, such as polyamine, catecholamine, and amino acids, were measured by the postcolumn detection method using 2-mercaptoethanol and OPA. ${ }^{4}$

Preparation of samples. Serum samples $(1 \mathrm{ml})$ were mixed with $0.6 \mathrm{ml}$ of $10 \%$ trichloroacetic acid (TCA) and centrifuged at $10500 \mathrm{~g}$ for $2 \mathrm{~min}$. The supernatant $(0.1 \mathrm{ml})$ was subjected to the HPLC. Similarly, urine samples were diluted tenfold with distilled water and analyzed by HPLC.

\section{Reaction mechanism}

HPLC conditions. For structure analysis of the histamine-OPA reaction product (fluorophore), a Capcellpak $\mathrm{C}_{18} \quad \mathrm{SG}-120 \quad(5 \mu \mathrm{m}, \quad 4.6 \mathrm{~mm}$ i.d. $\times 25 \mathrm{~cm}$, Shiseido, Tokyo, Japan) was used as the column, and $0.05 \mathrm{M}$ ammonium acetate $/ \mathrm{CH}_{3} \mathrm{CN}$ (gradient elution from $40 \% \mathrm{CH}_{3} \mathrm{CN}$ to $80 \% \mathrm{CH}_{3} \mathrm{CN}$ during $20 \mathrm{~min}$ ) was delivered as the eluent at a flow rate of $1.0 \mathrm{ml} / \mathrm{min}$. For detection, UV (254 $\mathrm{nm}$ and $360 \mathrm{~nm}$ ) and fluorescence ( $\mathrm{Ex}$ $360 \mathrm{~nm} / \mathrm{Em} 430 \mathrm{~nm}$ ) were used. LC/MS was performed under both the same reversed-phase HPLC conditions and the normal-phase HPLC conditions [column, Lichrosorb Si-60 $(5 \mu \mathrm{m}, 4.0 \mathrm{~mm}$ i.d. $\times 12.5 \mathrm{~cm}$, Kanto Chemical, Tokyo, Japan); eluent, ethyl acetate/

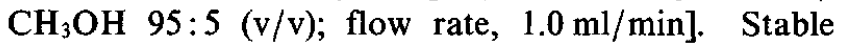
nonfluorescent products considered to be derived from the fluorophore were separated using a Develosil $5 \mathrm{C}_{18}$ $(5 \mu \mathrm{m}, \quad 4.6 \mathrm{~mm}$ i.d. $\times 15 \mathrm{~cm}$ and $10 \mathrm{~mm}$ i.d. $\times 25 \mathrm{~cm}$, Nomura Chemical, Seto, Japan) and $0.2 \%$ TFA aqueous solution/ $\mathrm{CH}_{3} \mathrm{CN}$ (gradient elution from $10 \% \mathrm{CH}_{3} \mathrm{CN}$ to $50 \% \mathrm{CH}_{3} \mathrm{CN}$ during $20 \mathrm{~min}$ ) as the eluent was delivered at $1.0 \mathrm{ml} / \mathrm{min}$ (analysis) or $5.0 \mathrm{ml} / \mathrm{min}$ (preparation). UV $(254 \mathrm{~nm})$ was used for detection.

Sample preparation. For the analysis of the histamine-OPA reaction product (fluorophore), $10 \mathrm{ml}$ of $0.2 \mathrm{M}$ propionate buffer ( $\mathrm{pH} 7.0$ ) containing $2.3 \mathrm{mM}$ histamine was mixed with $5 \mathrm{ml}$ of THF solution of OPA (mol ratio of 1, 2, 10 and 20 to histamine), and the reaction mixture was left at room temperature for $2 \mathrm{~min}$. An aliquot of the reaction mixture was subjected to the HPLC. For LC/MS, a similar procedure was performed with the same buffer containing $11.5 \mathrm{mM}$ histamine and OPA (mol ratio of 1,2 and 5 to histamine). The stable nonfluorescent products were extracted with
$40 \mathrm{ml}$ of benzene after $20 \mathrm{ml}$ of a THF solution of $1.2 \mathrm{~g}$ OPA was added to $40 \mathrm{ml}$ of $0.2 \mathrm{M}$ propionate buffer (pH 7.0) containing $0.2 \mathrm{~g}$ of histamine and the mixture had been left standing for $1 \mathrm{~min}$ at room temperature. The extract was dried with magnesium sulfate, and the solvent was removed under reduced pressure. The residue was separated by TLC [ethyl acetate $/ \mathrm{CH}_{3} \mathrm{OH}$, $5: 2(\mathrm{v} / \mathrm{v})]$ and then purified by HPLC. One powdered product (D1) and two oily products (D2 and D3) were obtained by freeze-drying of HPLC fractions.

$N M R$ analysis of the fluorophore. THF- $d_{8}$ solution (7.5 ml) containing $25 \mathrm{mg}$ of OPA was mixed with $15 \mathrm{ml}$ of $0.2 \mathrm{M}$ propionate buffer $(\mathrm{pH} 7.0)$ containing $80 \mathrm{mg}$ of histamine. After $1 \mathrm{~min}$, the reaction mixture was extracted with $10 \mathrm{ml}$ of $\mathrm{CCl}_{4}$. Magnesium sulfate and $0.1 \mathrm{ml}$ of acetic acid- $d_{4}$ were added to the extract. After $2 \mathrm{~h}$ at $-20^{\circ} \mathrm{C}$, the dehydrated extract was analyzed with NMR.

\section{Results and Discussion}

\section{Measurement}

Table 1 shows the fluorescence intensity (relative peak height) detected by the postcolumn addition of the OPA solution prepared using various solvents. The fluorescence intensity was higher for aprotic solvents such as DMF, dioxane, $\mathrm{CH}_{3} \mathrm{CN}$, and THF than for protic solvents such as water and alcohol. The highest fluorescence intensity was observed for reagent grade THF containing $0.025 \%$ of 2,6 -di- $t$-butyl-p-cresol (BHT) as a stabilizer. These findings suggest that OPA reacts mainly with histamine in the aldehyde form. Hayashi ${ }^{5}$ reported a postcolumn detection method of histamine with OPA solution using an acid-alcohol mixture $1: 1$ (v/v) as the solvent. However, this HPLC assay must be run under strict conditions, e.g., those related to $\mathrm{pH}$ and salt concentration of eluent.

When the concentration of the OPA solution in THF was changed stepwise from 0.05 to $2.0 \%$, the maximum fluorescence intensity was observed at the OPA concentration of $0.1 \%$. The optimum flow rate of the OPA solution was $0.6-0.7 \mathrm{ml} / \mathrm{min}$. As for the reaction

Table 1 Effect of several solvents for OPA solution (0.1\%) on relative peak height

\begin{tabular}{lc}
\hline Solvent & Relative peak height \\
\hline Water & 1 \\
Methanol & 7 \\
Ethanol & 23 \\
Acetone & 7 \\
Dimethylformamide & 52 \\
Dioxane & 61 \\
Acetonitrile & 34 \\
Tetrahydrofuran (HPLC) & 85 \\
Tetrahydrofuran (R.G.) & 100 \\
\hline
\end{tabular}

Sample (histamine solution, $1.1 \mu \mathrm{M}, 50 \mu \mathrm{l}$ ) was injected into the HPLC. 
Table 2 Capacity factor and relative response of histamine and biogenic amines obtained by the present HPLC method

\begin{tabular}{lcc}
\hline Amine & $k^{\prime}$ & Relative response \\
\hline Histamine & 3.20 & 100 \\
1-Methylhistamine & 3.17 & N.D \\
3-Methylhistamine & 3.17 & N.D \\
3-Methylhistidine & 0.42 & N.D \\
Histidinol & 2.97 & 75 \\
Serotonine & 6.83 & 0.06 \\
Catecholamine & 2.11 & N.D \\
Amino acids & $<1.00$ & N.D \\
Histidine & & 59 \\
Tryptophan & & 0.5 \\
Putrescine & 2.76 & N.D \\
Cadaverine & 2.77 & N.D \\
Spermidine & $10.00<$ & N.D \\
Spermine & $10.00<$ & N.D \\
$N$-Acetylputrescine & 0.58 & N.D \\
$N^{\text {-Acetylcadaverine }}$ & 0.66 & N.D \\
$N^{1}$-Acetylspermidine & 2.28 & N.D \\
$N^{8}$-Acetylspermidine & 2.45 & N.D \\
$N^{1}$-Acetylspermine & $10.00<$ & N.D \\
\hline
\end{tabular}

a. L-lysine, L-arginine, L-aspartic acid, L-threonine, L-serine, L-glutamic acid, L-proline, L-isoleucine, L-alanine, L-cystine, L-valine, L-methionine, glycine, L-leucine, L-tyrosine, L-phenylalanine, L-tryptophan.

temperature, the fluorescence intensity at $40-50^{\circ} \mathrm{C}$ was about 1.3 times that at room temperature. Although addition of BHT to THF increased the fluorescence intensity, the greater the BHT concentration, the more noise there was on the chromatogram. Therefore, reagent grade THF containing $0.025 \%$ BHT was used without any treatment. The mechanism of the increase in fluorescence intensity by BHT is not clear.

A good calibration curve passing the origin was obtained between the peak height on the chromatogram and the amount of histamine in the range of $10-1280 \mathrm{pg}$ $(r=0.999, n=8)$. The reproducibility (RSD) of the peak height on serial analysis for more than $20 \mathrm{~h}$ was 3.2 $4.5 \%$ (concentration level: 10, 20, 40,80,160,320,640 and $1280 \mathrm{pg} ; n=9)$. Therefore, the absolute calibration method using the peak height was considered to be applicable to the quantification. The lower detection limit was $5 \mathrm{pg}(S / N=3)$.

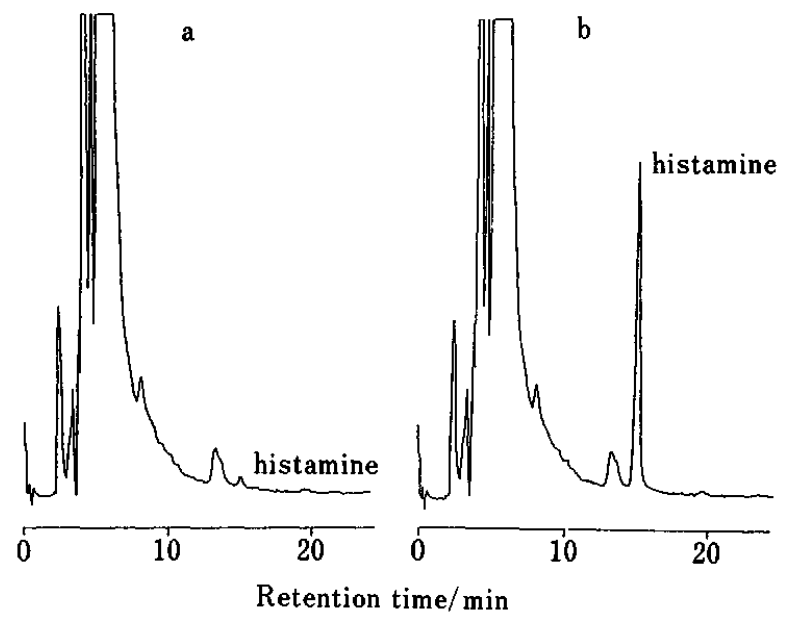

Fig. 1 HPLC chromatograms of serum samples: (a) blank serum; (b) serum spiked with histamine $(11 \mu \mathrm{M})$. Deproteinized serum $(50 \mu \mathrm{l})$ was injected into the HPLC.

The capacity factor $\left(k^{\prime}\right)$ and the fluorescence intensities for histamine and various other biogenic amines are shown in Table 2. As presumed from $k^{\prime}$, histamine can be distinguished from the other amines, except methylhistamine, by this method. As for methylhistamine, it will not interfere with the measurement because it produces no fluorophore under the reaction conditions. As shown in Table 2, the present method allows selective detection of compounds with a $\beta$ aminoethyl group at the $\beta$-position of the imino group on imidazole and indole such as histamine and histidine. Although Shore's method is similar to the present method, the former detects spermidine as well as histamine and histidine.

\section{Recovery test}

Histamine in human serum. Figure 1 shows chromatograms of pooled serum and histamine-spiked pooled serum. Histamine was clearly separated by the analysis within $20 \mathrm{~min}$, and the lower quantification limit was $1 \mathrm{nM}$. The recovery of histamine from histaminespiked serum in the range of about $7-110 \mathrm{nM}$ was $104-$ $114 \%$ as shown in Table 3. Though these values were slightly higher than the theoretical value, there was a good linear relationship between the spiked amount and the observed value. The intra-day and inter-day

Table 3 Recovery of histamine from human serum

\begin{tabular}{ccrrrrrrr}
\hline $\begin{array}{c}\text { Sample } \\
\text { No. }\end{array}$ & Added $(X) / \mathrm{nM}$ & \multicolumn{4}{c}{ Found $(Y) / \mathrm{nM}$} & & Mean \pm SD & $\begin{array}{c}\text { Recovery, } \% \\
\text { Mean } \pm \text { SD }\end{array}$ \\
\hline $1-5$ & \multicolumn{1}{c}{0} & 3.5 & 3.8 & 3.1 & 3.8 & 3.2 & $3.5 \pm 0.3$ & \\
$6-10$ & 7.0 & 11.6 & 11.2 & 11.7 & 11.6 & 11.3 & $11.5 \pm 0.2$ & $114.3 \pm 5.7$ \\
$11-15$ & 13.9 & 19.4 & 19.1 & 19.2 & 18.5 & 18.9 & $19.0 \pm 0.3$ & $111.5 \pm 3.6$ \\
$16-20$ & 27.8 & 34.7 & 34.3 & 33.9 & 34.0 & 34.0 & $34.2 \pm 0.3$ & $110.4 \pm 1.4$ \\
$21-25$ & 55.6 & 63.6 & 65.5 & 63.8 & 64.5 & 66.6 & $64.8 \pm 1.1$ & $110.3 \pm 2.2$ \\
$26-30$ & 111.2 & 118.7 & 118.6 & 118.7 & 122.0 & 117.9 & $19.2 \pm 1.4$ & $104.0 \pm 1.2$ \\
\hline
\end{tabular}

Regression equation: $Y=1.042 X+4.6, \mathrm{SD}=1.48, r=0.9994$. 


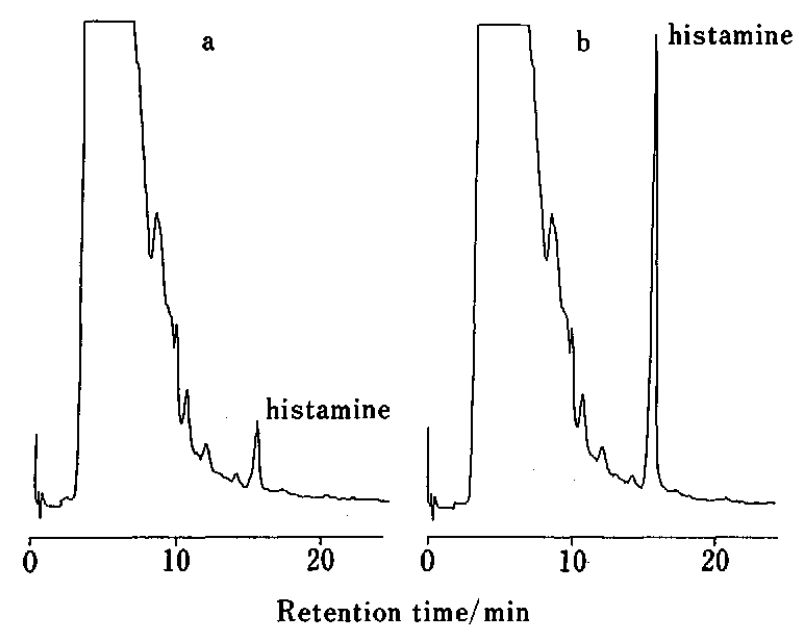

Fig. 2 HPLC chromatograms of urine samples: (a) blank urine; (b) urine spiked with histamine $(1.4 \mu \mathrm{M})$. Deprotenized sample of diluted urine was injected into the HPLC.

precision values for serum samples containing $27.8 \mathrm{nM}$ of histamine were $0.8 \%(n=5)$ and $3.3 \%(n=5)$, respectively. Histamine in human urine. Figure 2 shows chromatograms of pooled urine and histamine-spiked pooled urine. Since many interference peaks were observed, unlike blood samples, the urine samples need to be diluted tenfold to reduce the interference. The lower quantification limit was $10 \mathrm{nM}$. Table 4 shows the recovery of histamine from urine samples. The recovery of histamine in the range of about $170-2780 \mathrm{nM}$ was $99-102 \%$. There was a good linear relationship between the spiked amount and the observed value $(Y=1.00 X)$. The intra-day and inter-day precision values for urine samples containing $694 \mathrm{nM}$ of histamine were $0.9 \%(n=5)$ and $2.0 \%(n=5)$, respectively.

\section{Improvement in sensitivity}

Although the above method showed high sensitivity for histamine, we tried to improve it further. Figure 3 shows the time course of fluorescence intensity of the reaction mixture of $0.2 \mathrm{M}$ propionate buffer solution of histamine (pH: 3.5, 4.0, 4.5, 5.0, 5.5, 6.4, 6.8, 8.3) with THF solution containing $0.1 \%$ OPA. At each $\mathrm{pH}$, the fluorescence intensity reached the maximum after $3 \mathrm{~min}$

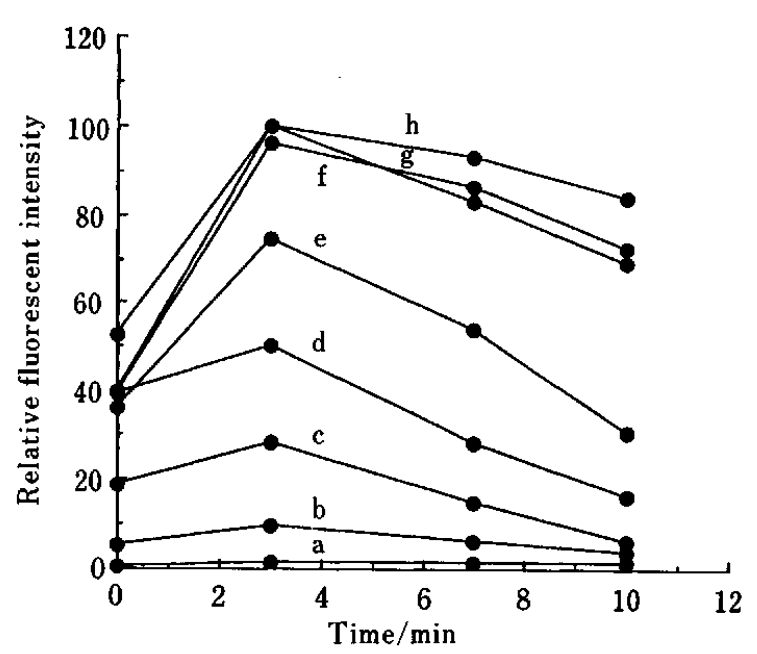

Fig. 3 Time course of fluorescence intensity at different $\mathrm{pH}$. pH: (a) 3.5 ; (b) 4.0 ; (c) 4.5 ; (d) 5.0 ; (e) 5.5 ; (f) 6.4 ; (g) 6.8 ; (h) 8.3. As the control, the fluorescence intensity at $\mathrm{pH} 8.3$ was used and measured at $\operatorname{Ex} 360 \mathrm{~nm} / \mathrm{Em} 430 \mathrm{~nm}$. A histamine concentration, $55.5 \mu \mathrm{M}$.

and decreased thereafter. The fluorescence intensity of this reaction depended on $\mathrm{pH}$, reaching a maximum at $\mathrm{pH} 7-8$. The half-life of fluorescence was estimated to be $15-20 \mathrm{~min}$. Therefore, after alkaline solution was added to the column eluate of this HPLC system to adjust the $\mathrm{pH}$ to about 7 , THF solution containing $0.1 \%$ OPA was delivered (2-step postcolumn reaction). Compared with the original method, the sensitivity increased about twofold, and the lower detection limit became $2 \mathrm{pg}$.

\section{Reaction mechanism}

The HPLC chromatogram of the reaction mixture of $0.2 \mathrm{M}$ propionate buffer containing histamine and THF solution of OPA shows two fluorescent peaks (P1, P2). $P 1$ decreased and $P 2$ increased with an increase in the OPA concentration. Reversed-phase LC/MS of P1 showed ions at $m / z 228\left[\mathrm{M}+\mathrm{H}_{2} \mathrm{O}+\mathrm{H}\right]^{+}, 210,182,146$, $116,95,81$ and 68 , and that of $P 2$ showed ions at $m / z 362$ $\left[\mathrm{M}+\mathrm{H}_{2} \mathrm{O}+\mathrm{H}\right]^{+}, 344,326,231,210,135,116,95$ and 68 . In addition, normal-phase LC/MS of $\mathrm{Pl}$ showed ions at $\mathrm{m} / \mathrm{z} 210[\mathrm{M}+\mathrm{H}]^{+}, 182,116$ and 81 . These results suggested that this reaction initially produces a $1: 1$

Table 4 Recovery of histamine from human urine

\begin{tabular}{ccrrrrrrr}
\hline $\begin{array}{c}\text { Sample } \\
\text { No. }\end{array}$ & Added $(X) / \mathrm{nM}$ & \multicolumn{4}{c}{ Found $(Y) / \mathrm{nM}$} & & Mean \pm SD & $\begin{array}{c}\text { Recovery, } \% \\
\text { Mean } \pm \text { SD }\end{array}$ \\
\hline $1-5$ & 0 & 140 & 152 & 148 & 176 & 188 & $161 \pm 18$ & \\
$6-10$ & 173 & 317 & 337 & 337 & 340 & 360 & $338 \pm 14$ & $102.3 \pm 5.2$ \\
$11-15$ & 347 & 490 & 508 & 524 & 525 & 530 & $515 \pm 15$ & $102.3 \pm 3.5$ \\
$16-20$ & 694 & 894 & 840 & 867 & 867 & 867 & $867 \pm 17$ & $101.7 \pm 3.9$ \\
$21-25$ & 1388 & 1520 & 1533 & 1591 & 1603 & 1621 & $1573 \pm 40$ & $101.8 \pm 1.9$ \\
$26-30$ & 2775 & 2907 & 2910 & 2993 & 2917 & 2873 & $2920 \pm 40$ & $99.4 \pm 1.9$ \\
\hline
\end{tabular}

Regression equation: $Y=0.995 X+171, \mathrm{SD}=13.6, r=0.9999$. 

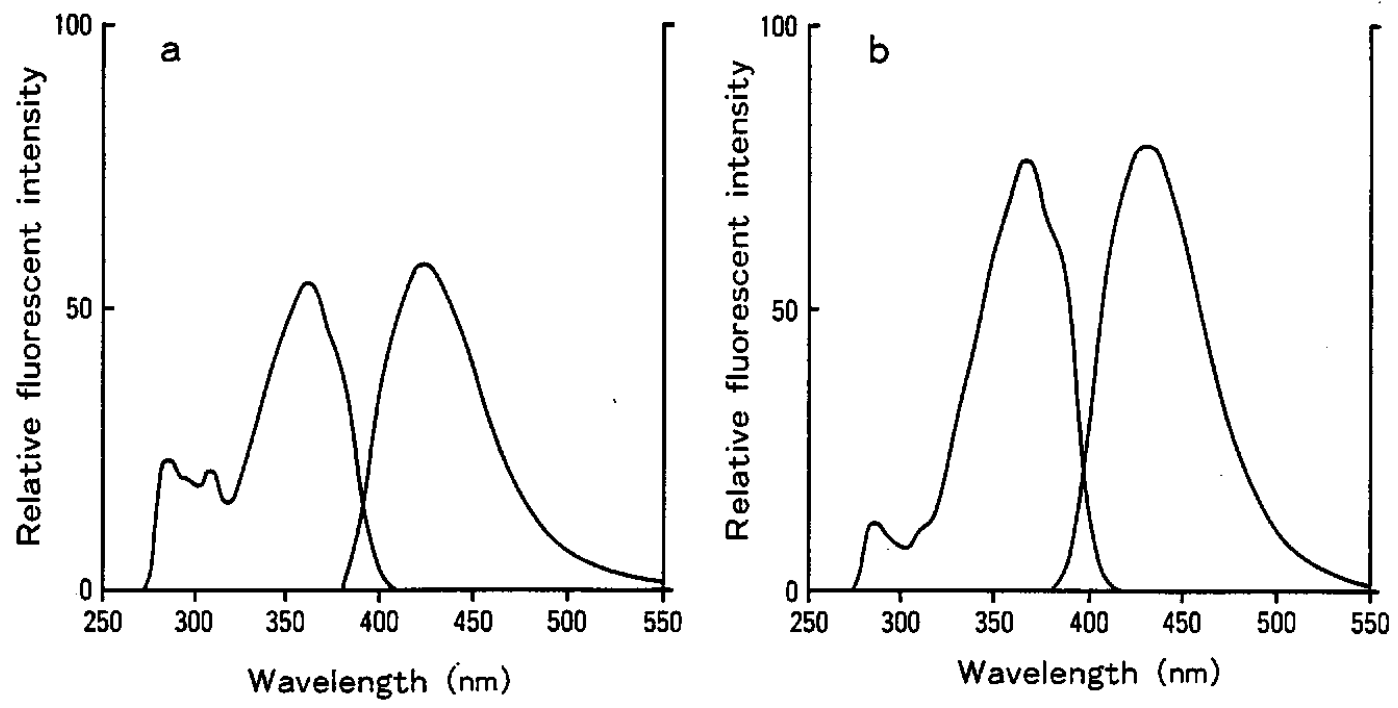

Fig. 4 Excitation and emission spectra of the histamine-OPA reaction mixture. (a) P1-rich mixture; (b) P2-rich mixture.

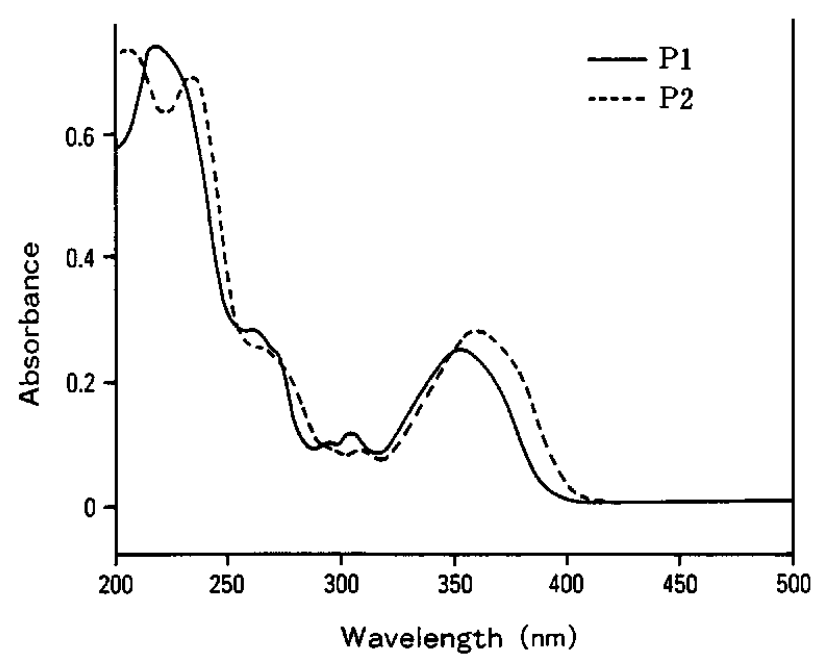

Fig. 5 UV spectra of histamine-OPA reaction products.

histamine-OPA addition product (P1, fluorescent, intermediate) and then a 1:2 histamine-OPA addition product ( $\mathrm{P} 2$, fluorescent). $\quad \mathrm{P} 2$ or the mixture of $\mathrm{P} 1$ and $\mathrm{P} 2$ is considered to be the fluorophore detected by HPLC. The fluorescent spectra of P1-rich and P2-rich mixture are shown in Fig. 4, and their UV spectra, obtained using a photodiode array detector, in Fig. 5.

$\mathrm{P} 1$ was extracted with $\mathrm{CCl}_{4}$ from the cooled reaction mixture together with other minor components and was measured by NMR. NOE correlation and spin-spin coupling correlation indicated the structure of the major component $P 1$ to be 4, as seen in Fig. 6. NMR analysis revealed that the structures of the nonfluorescent products are 10 and 11 (Fig. 6). The NMR data proving the structures are shown in Fig. 7. D1 was the stereoisomer 10a. D2 was a mixture of 10b and 10c $(2: 3)$. D3 was a mixture of 11a and 11b $(7: 5)$. These results led to the reaction course shown in Fig. 6 . First, condensation between histamine and OPA produces cyclic intermediate 1. This intermediate is dehydrated, producing fluorophore 2 , which is considered to be the intermediate in this reaction. [Compound 4 is considered to be produced from intermediate 2 after ringclosing dehydration. However, since ions at $\mathrm{m} / \mathrm{z} 228$ $\left[\mathrm{M}+\mathrm{H}_{2} \mathrm{O}+\mathrm{H}\right]^{+}$and $m / z 210[\mathrm{M}+\mathrm{H}]^{+}$were obtained by reversed-phase LC/MS and normal-phase LC/MS, respectively, a reversible reaction involving $\mathrm{H}_{2} \mathrm{O}$ may occur between 3 and 4.] Next, another molecule of OPA is added to 2, producing fluorophore 6 via ketoform tautomer 5 (the presence of the determined structures 10 and 11 in Fig. 6 supports the structure and presence of 6). This structure 6 probably produces fluorophore 8 or 9 via compound 7, although clear evidence is lacking to decide between structures 8 or 9 . These results suggest that $P 1$ has the structure of 2 or 4 , and $P 2$ of 6 or perhaps of 8 or 9 . The structures $2,4,6$, 8 and 9 are the isoindole type. Studies on primary amines and OPA in the presence of the thiol component showed marked fluorescence due to the isoindole structure. ${ }^{6-8}$ Rönnberg et $a l .{ }^{9}$ reported production of a histamine-OPA $(1: 1)$ addition product, followed by production of the $1: 2$ product. However, their estimated structures differed from ours. After treatment with a strong alkali followed by a strong acid, the $1: 2$ product gave a stable substance emitting intense fluorescence. In our method, the reaction is done in neutral solution, and both the $1: 1$ and $1: 2$ products are fluorescent with the same fluorescence spectra. These addition products lost their fluorescence under strong acidic condition, being rapidly degraded. Therefore, the fluorescence substance obtained in this study probably differs from that reported by Shore et al. or Rönnberg et al.

We thank Dr. Masaru Ogata of Shionogi Research Laboratories and Dr. Kazumasa Hirauchi of our department for their valuable advice and discussion throughout this study. 


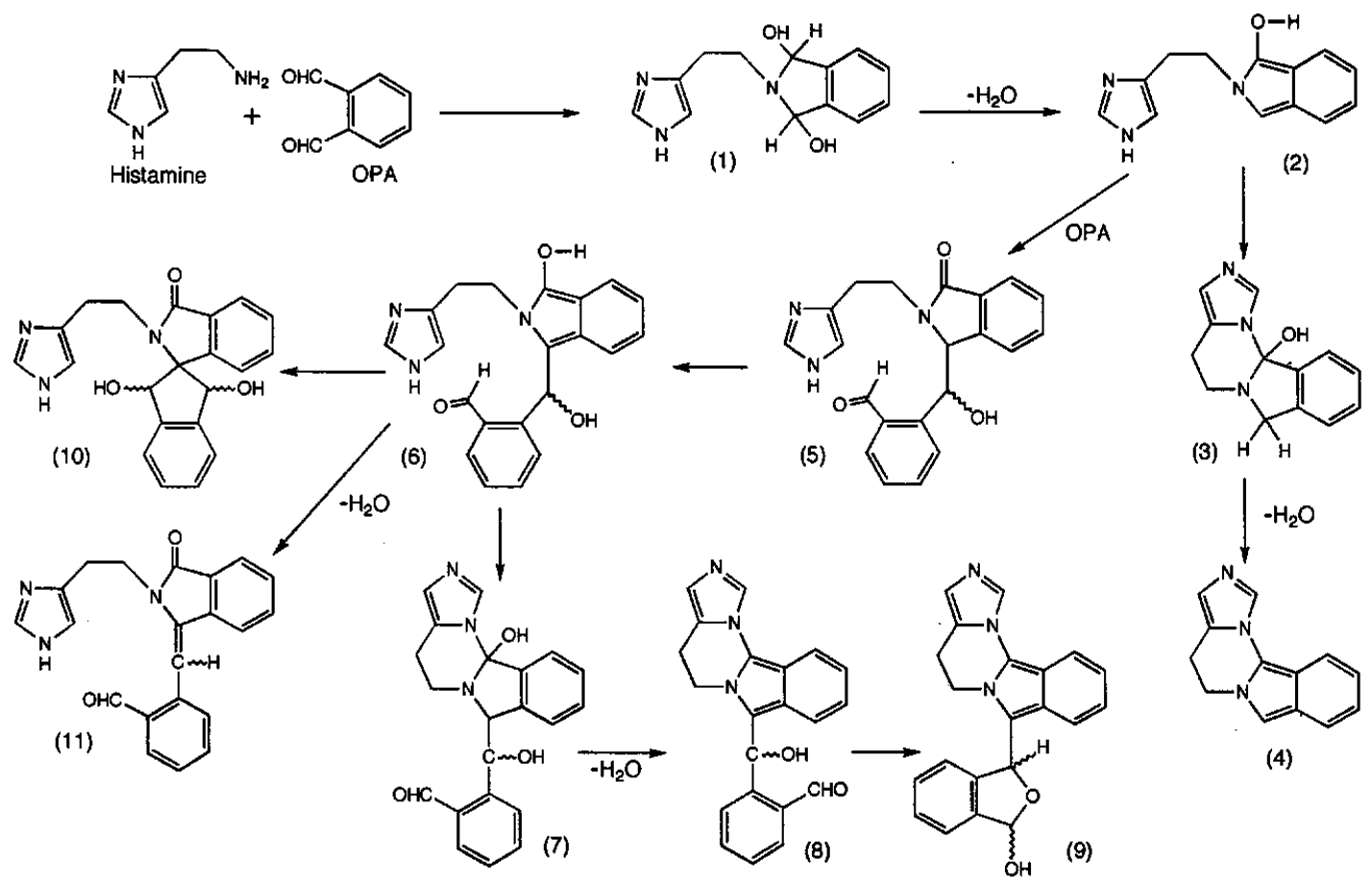

Fig. 6 Proposed mechanism of the fluorescence reaction of histamine with OPA.

(4) ${ }^{1} \mathrm{H}$ Data (in $\mathrm{CCL}_{4}-\mathrm{THF}-\mathrm{CD}_{3} \mathrm{COOD}$ at $20^{\circ} \mathrm{C}$ )<smiles>CCNCC</smiles>

(10: three stereoisomers $\mathrm{a}, \mathrm{b}$, and $\mathrm{c}$ ) ${ }^{1} \mathrm{H}$ Data (in $\mathrm{CD}_{3} \mathrm{OD}$ at $20^{\circ} \mathrm{C}$ )
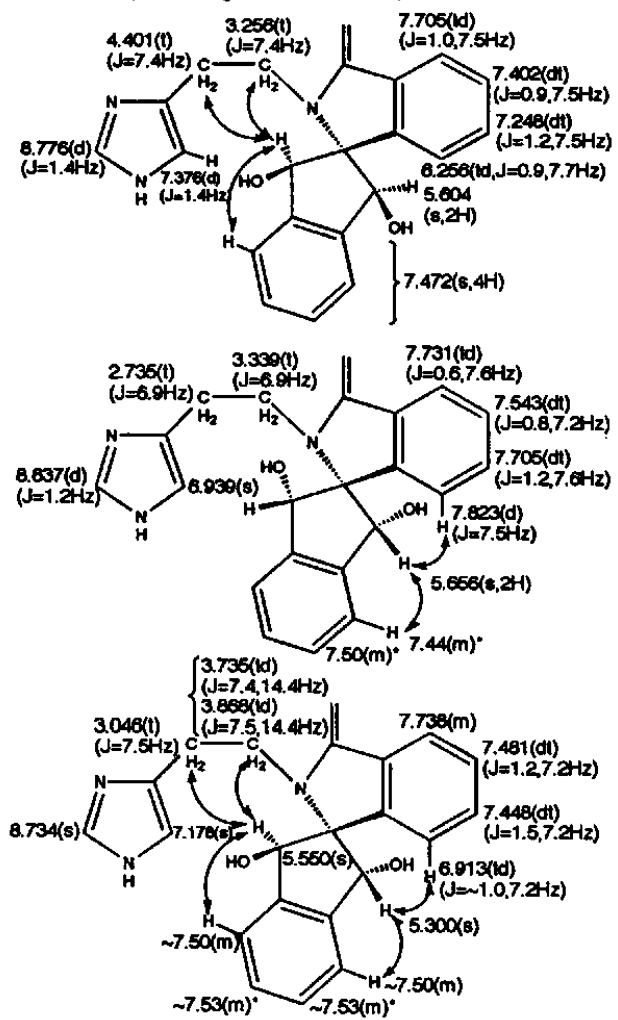

(10b)

(10a)

(10c)

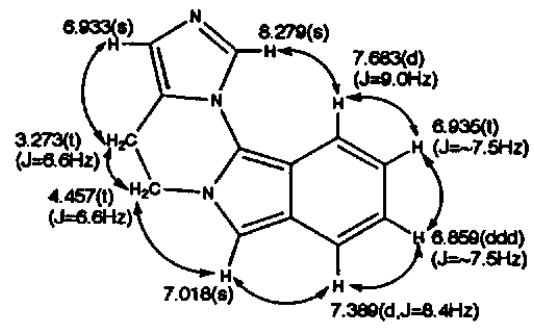

${ }^{13} \mathrm{C}$ Data (in $\mathrm{CD}_{3} \mathrm{OD}$ at $28^{\circ} \mathrm{C}$ )<smiles>C=C1c2ccccc2C2(O)C3=C(CCN1C(=O)c1ccccc12)N=CON3</smiles>

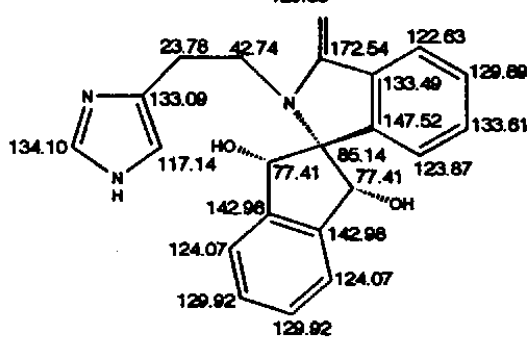

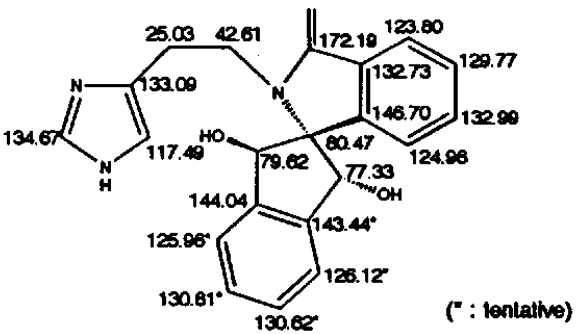


(11: two geometric isomers $a$ and $b$ )

${ }^{\mathrm{T}} \mathrm{H}$ Data (in Acotone- $\mathrm{d}_{6}$ at $20^{\circ} \mathrm{C}$ )

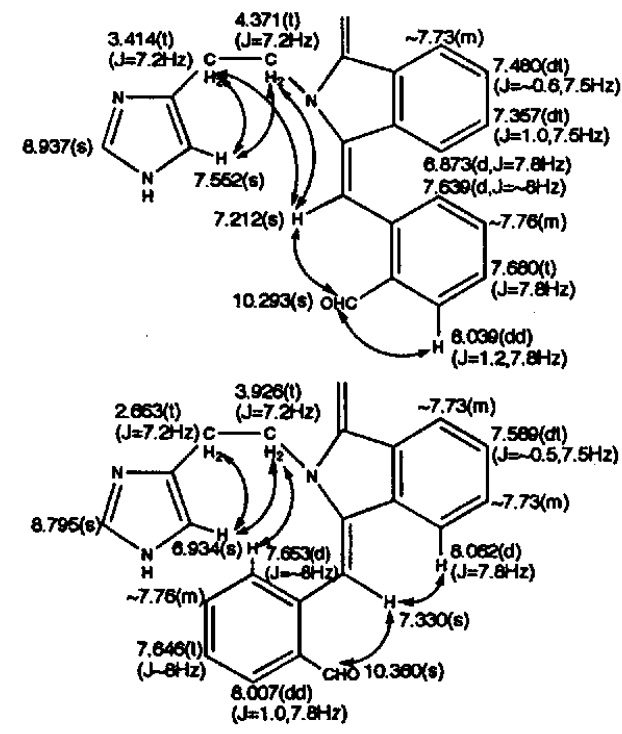

${ }^{13} \mathrm{C}$ Data (in Acetone- $\mathrm{d}_{6}$ at $20^{\circ} \mathrm{C}$ )

(11a)

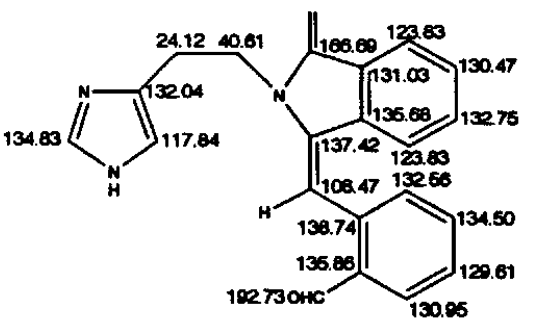

(11b)

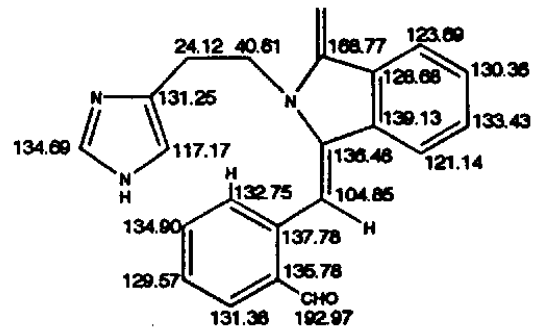

Fig. 7 NMR data and NOE correlation of products 4, 10 and 11.

We also thank Mr. Kouji Iwatani of Shionogi Research Laboratories for his useful suggestions and for the measurements of LC/MS.

\section{References}

1. A. Yamatodani, H. Fukuda, H. Wada, T. Iwaeda and T. Watanabe, J. Chromatogr., 344, 115 (1985).

2. P. A. Shore, A. Burkhalter and V. H. Cohn. Jr., J. Pharmcol. Exp. Ther., 127, 182 (1959).

3. R. S. McDonald and E. V. Martin, Can. J. Chem., 57, 506 (1979).
4. J. R. Benson and P. E. Hare, Proc. Natl. Acad. Sci. U.S.A., 72, 619 (1975).

5. M. Hayashi, Japan Kokai Tokkyo Koho JP 86254852.

6. S. S. Simons, Jr. and D. F. Johnson, J. Org. Chem., 43, 2886 (1978).

7. S. S. Simons, Jr. and D. F. Johnson, Anal. Biochem., 82, 250 (1977).

8. S. S. Simons, Jr. and D. F. Johnson, Anal. Biochem., 90, 705 (1978).

9. A. L. Rönnberg, C. Hansson, T. Drakenberg and R. Hakanson, Anal. Biochem., 139, 329 (1984).

(Received November 22, 1993)

(Accepted December 27, 1993) 